\title{
Community Perceptions and Understanding of Vulnerability in Drought Prone Gamo Lowlands, Southwest Ethiopia
}

Thomas Toma Tora ( $\square$ thomastoma7@gmail.com )

Arba Minch University https://orcid.org/0000-0003-0842-6324

Degefa Tolossa Degaga

Addis Ababa University

Abera Uncha Utallo

Arba Minch University

\section{Research}

Keywords: Community, Drought, Gamo lowlands, Households, Perceptions and understanding,

Vulnerability

Posted Date: January 6th, 2021

DOI: https://doi.org/10.21203/rs.3.rs-137317/v1

License: (c) (i) This work is licensed under a Creative Commons Attribution 4.0 International License.

Read Full License 


\section{Abstract}

The conceptual root of vulnerability dates back to the 1970 s in social sciences. Vulnerability is a multidimensional and determinant precondition for disaster occurrence. Gamo lowlands are exposed to multiple vulnerabilities. The objective of the study was to assess community perceptions and understanding of vulnerability in drought-affected rural Gamo lowlands. A community-based crosssectional survey design and mixed methods approach were implemented in the study. Four staged multistage sampling was employed to identify respondent households. Into four study sites, sample households were allocated proportionally by lottery method. Data were gathered from 285 lowland rural households. The structured survey questionnaire, KII, FGD, and informal interview were used to collect primary data. Data were analyzed both qualitatively and quantitatively. SPSS version 23 was employed for descriptive statistical duties. $68.1 \%$ of households were found at low educational status with 46 years of average age. Locally, people perceive and understand vulnerability as exposure to drought hazard, rainfall inconsistency, the prevalence of human and animal diseases, livelihood insecurity, food shortfalls, poor income, lack of access to market, landholding, and livestock ownership which are schematized by vulnerability perception pathways that delineate its extent. The findings also showed that all households are not equally vulnerable as $96.5 \%$ of the studied households stated differential idiosyncrasy of vulnerability. Old aged, small-sized, and female-headed households with no supportive force were found to be more vulnerable. For better resilience, enhancing communities' perceptions and understanding of vulnerability via continuous awareness creation by all the concerned stakeholders is recommended as the majority were lowly educated.

\section{Introduction}

Vulnerability is originated from Latin term "vulnus (vulner)" meaning wound (Slater 2016; Wisner 2016); vulnerabilis (Coppola 2007) or vulnerare (Mynarska et al. 2015) that means to wound. Conceptually, the root of vulnerability dates back to the 1970 s in social sciences. The scenario was to respond against pure hazard-oriented perception of disaster risk. Since 1980s, such a hazard-oriented understanding is shifted to vulnerability focused paradigm alternatively following technically intervening challenges against hazard-oriented views (Schneiderbauer and Ehrlich 2004). This new paradigm in emergency management is advanced by scholars and practitioners as a core theme in the introduction of vulnerability connotation with better capturing and perception of disasters' social construction (McEntire et al. 2010).

Scientific communities opined that vulnerability is multi-dimensional, developmental, cross-scale, and interdisciplinary (Mafi-Gholami et al. 2016, p.3), 'elusive' Moret 2014 p, 4; Thabane 2015 p. 2; 'slippery' (Cannon 2008, p. 2; Fischer and Chhatre 2016, p. 2), 'contested' (Thywissen 2006 as cited in Angela et al. 2015, p.12), 'complex concept' (Jha 2010, p. 19; Marchezini et al. 2017, p. 28; Wisner 2016, p. 1) as well as 'multi-faceted phenomena' (Lewis and Kelman 2011).

Vulnerability is determinant precondition for a disaster to occur. Scholars argue for such scenarios in which "a significant number of vulnerable people experience a hazard and suffer severe damage and/or 
disruption of their livelihood system in such a way that recovery is unlikely without external aid". In this context, risk of disaster in a mathematical pseudo equation is notified with three elements; $\mathrm{R}=\mathrm{H} \times \mathrm{V}$. In the equation, risk is the compound function of specific hazard and vulnerable people who occupy the space and time of exposure to that specific hazard (Wisner et al. 2004, p. 45).

Community perception on climate induced risks is manifested in diverse ways and attributes. Politically, culturally, and in terms of physical environment, the issue has been elaborated. Such climate related circumstances pose susceptible sections of the society to perceive themselves exposed to climate emanated risks as indicative of social vulnerability (Akerlof et al. 2015). Understanding vulnerability of rural areas is vital in multiple perspectives. Amongst, its role in the development of proper risk aversion mechanisms is duly addressed (Jamshed et al. 2020).

Vulnerability to water scarcity is perceived differentially in rural India as a result of location, farm size, level of income, and with lesser degree by demographic attributes like age, sex, and education (Singh et al. 2018). Risk perception, as scientifically evidenced, is among the factors that strongly affect household level adaptation strategies against natural hazards where flood prone African city dwellers are well cognizant of their vulnerability (Okaka and Odhiambo 2019). Others on the other hand state that perceiving risk is changeable through time in accordance with the occurring natural hazards and variations in people's perception take place as a result of differential magnitude of vulnerability with socioeconomic characteristics (Balteanu et al. 2014). More recently, Ghana's women farmers in the context of climate change express their perceptions of decrement in rainfall trend as a commonly occurring norm (Lawson et al. 2020). In dry lands of Africa, drought hazard is a driving force that challenges livelihood security. The best fitting instance of this scenario is that of pastoral livelihood loss in the High Atlas Mountains of Morocco where drought is reported as a source of herdsmen livelihood insecurity (Martin et al. 2014). In the Horn of Africa on the other end, above 40\% of the population resides in drought affected areas where the community is impoverished (International Institute of Rural Reconstruction 2010).

People, their perceptions as well as knowledge are in the middle of crucial vulnerability concerns in the review of social vulnerability (Singh et al. 2014). Seemingly, perception and implementation variations of households highly matter in predisposition to food insecurity in rural Ethiopia for what agrarian societies are characteristically reported with different perceptions across agro-ecologies (Abera 2013). In this regard, perceptions of households with differential characteristics are also genuine in Southern Ethiopian lowlands where households expressed their perceptions for local climate variability related interrogations as good times only remained as past history, rainfall both in its amount and frequency (rainy days) has been observed with decreasing tendency, and bad weathers are the implications of God's punishment (Aklilu and Alebachew 2009). Ethiopian farmers perceive drought impacts as augmenting average temperature and degraded environmental resources like water quality, pasture, and forest at a maximum extent with meager proactive preparedness on the contrary (Habtamu et al. 2018). These conditions further necessitate vitally investigating local communities' perceptions and understanding of climate induced health hazards for effective disaster risk management (Ncube and Tawodzera 2019). 
Smallholder farming households perceive climate change and its results with varieties of manifestations in Ethiopia. Low amount of rain, natural hazards like drought and flood, high disease onsets, and declined crop yields are among such resultants. The perceptions are characterized with differential levels. Profiles of farmers like education and strength of social ties determine people's perception on changing and varying climate states with negating impacts on local agricultural activities. The pitfalls are disproportionally severe in the arid, partially arid and sub-humid dry lowlands of the country. To tackle such adversities, beyond awareness creation, customized endeavors targeting on capital assets, population migration and resettlement, and livelihood source diversifications as adaptive strategies are demanding (Mekonnen 2018; Nega et al. 2015; Yoseph et al. 2015; Assefa et al. 2008).

Furthermore, lowlands inhabited by pastoralists and highlands occupied by dense population are severely vulnerable to drought; insidiously happening natural hazard in Ethiopia (MoARD 2010; World Meteorological Organization 2012). Such situations are among recurring impediments of livelihood security in the country where large segments of population are exposed to risks. Gamo areas, mainly the lowlands have been exposed to diverse vulnerabilities such as drought hazard, animal and human maladies, livelihood security challenges, and food insecurity (National Disaster Risk Management Commission (NDRMC) 2019; FAO 2017; DRMFSS 2011; NURU International 2015; and Lomboll and Pound 2014).

Vulnerability assessment poses five important questions with expected replies in the end. Three of these questions namely; "What is the extent of vulnerability? What are the sources of vulnerability? and Who is vulnerable? (Hoddinott \& Quisumbing 2003, p. 46 as cited in Moret 2014, p. 1) are duly considered in this work. Contextually Chaudhury (2017) also recommends priority for identifying the existing specific type of vulnerability in vulnerability reduction duties.

Further studies on perception of cattle farming households on risk and its management strategies in the context of Ethiopia are recommended in literature as only a little is known about farmers' perception without recent empirical investigations (Kinfe et al. 2018; Kinfe and Tewodros 2014). For that reason, this study was conducted to assess community vulnerability perceptions and understanding based on timely collected survey data of households' socioeconomic characteristics subsuming livestock.

A lot of scholars in different fields have contributed on knowledge generation on Gamo highlands. Nevertheless, drought susceptible Gamo lowlands receive little of scientific investigation. This study tried to give more attention to these areas to fill the lacuna of scientific literature. The main objective of the study was to assess community perceptions and understanding of rural vulnerability in drought affected Gamo lowlands. Basically, the intent was to investigate how and to what extent Gamo lowland communities perceive and understand the existing vulnerabilities in accordance with the situations of the study areas. The extent of households' perceptions and understanding on rural vulnerability was examined in two perception pathways of vulnerability. The topic is believed to be important to help resilience building of vulnerable communities through continuous awareness enhancement and effective coping strategies. 


\section{Materials And Methods}

\section{Description of the Study Areas}

The study was conducted in Gamo lowlands of recently structured Gamo Zone, located in the Southwestern part of Ethiopia in Southern Nations Nationalities and Peoples Regional State with the zonal capital Arba Minch located at $505 \mathrm{~km}$ and $275 \mathrm{~km}$ away from Addis Ababa and Hawassa. The total population of the Gamo zone is male 802,558 female 810,956 total $1,613,514$. The study districts, Mirab Abaya and Boreda have the total population of male 102,108 female 100,830 total 202,938 (Gamo Zone Finance Department 2020).

The people at the study areas are engaged both in crop cultivation and animal husbandry. Livelihood of the community is dependent on subsistence mixed farming that is exposed to recurrent drought which causes scarcity of water that in turn adversely impacts people's livelihoods. Inhabitants of the study kebeles are resettled people with their origins either from the uplands kebeles in the study districts, from other districts of the study zone, South Nations Nationalities and Peoples' Region as well as from other far distant areas of the country. As a consequence, the study households were characteristically diverse in their ethnicity, religion, language and other sociodemographic attributes.

The areas that Gamo lowlands (below 1500 meter) include are found in nine of the fourteen rural Gamo zone districts namely Boreda, Kucha, Kucha Alpha, Mirab Abaya, Dera Malo, Arba Minch Zuria, Geressie, Kamba, and Martha Garda with altitudinal range of 638 meter to 1500 meter. The study districts are vicinal to each other and share common borders with other districts. Accordingly, Mirab Abaya district is bordered in the East and South by Lake Abaya, that naturally separates the district from Oromia region. Additionally, Arba Minch Zuria district in the South, Chencha district in the West, in the Northwest by Boreda district, and by Wolayita zone in the North. Boreda district on the other side is bounded with Wolaita zone in the North and Northwest, Kucha district in the West, Mirab Abaya district in the East and Southeast and Kogota district in the South. Fig.1 Location Map of Study Areas

\section{Research Design, Approach, and Sampling Procedure}

Community based cross-sectional survey research design was employed in the study. The research approached considered was mixed methods research approach that is used to understand how and what the local communities perceive as risk and hazard that impacts their everyday life in relation with disaster risk reduction (lloka 2017). On the other end, Almalki (2016) opines as mixed methods research approach is a potential source of deep and broad information beyond singular approaches. Amongst the strategies of mixed research, concurrent triangulation was employed to collect and analyze both qualitative and quantitative data concurrently in terms of interactions (Creswell 2014).

While sampling, how and how many to select the representative population is a big concern. The selection of study areas was purposively done in order to procure the information that can best help attain the purpose of study (Kumar 2011). In Woreda Disaster Risk Profile (WDRP), a comprehensively 
employed disaster reduction program with data used as research baseline, Mirab Abaya and Boreda districts are among the districts prone to drought and other hazards where most households are vulnerable to drought corollaries (NDRMC 2019). These districts were also among the prioritized intervention areas in the former Gamo Gofa zone for disaster prevention and coping strategies such as school feeding program since January 2016 (Gamo Zone Education Department 2019). Besides, the selected districts have many vulnerable lowland kebeles. $62.5 \%$ of Mirab Abaya district and $53 \%$ of Boreda district is agro-ecologically lowland (kolla) where many rural kebeles are exposed to a plethora of vulnerabilities.

Multi-stage sampling, "a sampling within the sample"; widely used in household surveys where population is scattered over a wide area involving three or more stages of sampling (Alvi 2016; Chauvet 2015) was employed to identify the targeted participants stagewise. The sample frame used was list of the study population households accessed from the documents available in kebele administrative offices. Four staged sampling procedures were formulated to reach at the required sample representatives. The first stage was identifying districts with vulnerable kebeles from Gamo lowland areas. In the newly structured Gamo Zone since January 09, 2019, there are 9 rural administrative districts namely Arba Minch Zuria, Kucha, Kucha Alpha, Dera Malo, Boreda, Mirab Abaya, Geressie, Kamba, and Martha Garda which are comprised of lowland kebeles with varying extent of drought vulnerability among the 14 rural districts.

Secondly, vulnerable rural kebeles were identified. In Mirab Abaya district, 15 of the 23 rural kebeles are found in low lying areas. Even though, some of these kebeles practice small scale traditional irrigation schemes that help them relatively to cope with vulnerability and livelihood security related constraints. Recurrently drought prone kebeles in the district include Fetele Doronje, Doshe, Korga Geramo, Yayike, and Kolla Barana amongst which the prioritized ones were Fetele Doronje and Doshe based on the severity of vulnerability. Drought with its increasing trends of effects, among the other disasters in these kebeles has been presented in WDRP since 1961 in Doshe and 1969 in Fetele Doronje (NDRMC 2019).

In Boreda district, there are 28 rural kebeles of which 13 are found agro-ecologically in drought prone lowland areas. More vulnerable rural kebeles to drought hazard and related impacts are Tentelle, Dugana Gamero, Gumgumuta, and Dubana Bulo wherein the first two were taken as sample kebeles. In the database profile of NDRMC (2019), these kebeles are presented with drought and human and livestock diseases since 2008 with worst period of 2015. Totally, Fetele Doronje, Doshe, Tentelle, and Dugana Gamero were purposively taken as sample vulnerable lowland kebeles from both districts. Population homogeneity is considered to prioritize these kebeles purposely. Living in lowland agro-ecology, dependence on similar livelihood activities (subsistence mixed farming), relative ease of access, predisposition to drought and water scarcity are among the facets of the homogeneity. Also, these kebels were among the primarily focused kebeles for drought affected students in disaster responding strategies like school feeding program (Gamo Zone Education Department 2019). 
Thirdly, targeted population was identified. From both Mirab Abaya and Boreda districts, the study population from the top vulnerable rural lowland kebeles were selected and lastly, sample size determination was conducted. Commonly recommended technique of sample size determination, applying formula, is employed to decide the sample size. Israel (2013) as cited in Getcahew et al. (2018) illustrated easier and simplified formula to compute representative sample size from finite population. In order to nominate the calculated and proportionally allocated household survey respondents, lottery method was employed. Consequently, the calculated 285 respondents were allocated proportionally in to the study kebeles as follows.

\section{Data Collection and Analysis}

The necessary data to attain the study objective were collected both from primary and secondary sources. Household survey respondents, key and informal informants, and focus group discussants were the principal sources for primary data acquisition. Secondary data were collected from both published and unpublished germane materials. Instruments employed for data collection include structured survey questionnaire, key informant interview, focus group discussion, direct observation, and informal interview.

Both qualitative and quantitative data analysis techniques were employed in the study. Qualitatively, interpretive analysis via triangulation was widely conducted. In such a way, verbal or textual descriptions, discussions, annotations, and narrations were exhaustively done to link statistical findings of structured household survey questionnaire. Quantitative data were analyzed first generating descriptive statistics and triangulated by qualitative data as per the nature of the objective.

Descriptively, demographic and socioeconomic characteristics of respondents were generated by SPSS software. SPSS software version 23 is used for descriptive statistical duties wherein editing, numerically anchoring, categorizing, entering, and cleansing survey questionnaire data were conducted ahead of the analysis. Microsoft excel is also used to recode the numerical weighting of Likert scale in a way that the most (5) and least (1) favorable responses of households for each Likert type item were assigned showing the intensities of responses.

\section{Results And Discussion}

\section{Demographic and Socio-Economic Characteristics of Respondent Households}

The age of sample respondents is found among the vital attributes of the household survey. The survey finding showed that the minimum and maximum ages of respondents were 20 and 90 respectively while the mean was 46 . There is a nearer convergence of finding for this characteristic with what Alemayehu et al. (2020) found out wherein the lowest and average ages were 20 and 46.8 for the surveyed households. Divergently, the mean age of respondents was higher than the finding of Wuletaw et al. (2019) and lower 
than that of Habtamu et al. (2018) which respectively showed households' average age of 43.8 and 51.1 years. Greater number of the households (55.8\%) were aged between $40-54$ years.

The sex composition on the other hand was found as $90.5 \%$ for male headed and the remaining $9.5 \%$ was the share of female headed counterparts. The study conducted by Kidane et al. (2019) shows mixed subsistence farming agricultural activities as basic livelihood sources. Coincidingly, for their survival, the study households have been engaged on diverse livelihood activities in which the lions share goes to farming in which basically both crops and animals were being farmed in subsistence mixed modality by the targeted population exceeding $97 \%$.

Lowland settled people in Ethiopia are primarily pastoralist nomads who seasonally shift their places to areas where pasture and water are available for their animals (Menberu 2014). The survival style of most Gamo lowland households does not agree with this report except some cases of Tentelle rural kebele where only animal raisers from Guji and Sidama original areas reside. Still, it is common for these people at Tentelle kebele to move to shores of Lake Abaya as per the commencement of dry season to get pasture and water for the animals they own. Vital pieces of information from FGD and KII participants strengthen this condition as it is usual for these people to migrate to the mentioned preferable area from December to April every year until summer rain starts. Though this way of living is seemingly opted as vulnerability management practice by almost all nomadism-based households, it presently has other ills at the destination.

Other informal informants like school directors and supervisor of Tentelle kebele strengthened about the odds of such migration. Most students follow their families and go to Lake Abaya area which makes absenteeism and dropout rates among the highest in Boreda district. One of the researchers (corresponding author) was familiar with this educational anomaly during his leadership and professional duties in the district for about a decade (2006-2015). As observed in the field, the misery of water paucity is much severe in the kebele hit hardest from all the study sites. Mainly, the situation is too hard for disproportionately vulnerable and thirsty school children around empty water pipes and pregnant women who struggle for tentatively available impure under sand water that solely exists at rainy times as can be seen in Figure 2. Fig. 2 Some Observations on Water Tragedy in Tentelle Kebele Source: Field Photo (2020)

Family size is an important variable to explain household vulnerability. The mean and standard deviation of family size were found to be 6.76 and 2.375 respectively. This average family size was higher than both the rural national (5.1\%) and Southern Ethiopian regional (5.5\%) average household figures (CSA and World Bank 2013). Households whose family members are fewer than three and five and above might be considered as small and large average household sizes respectively. Such characteristics are clear states of unequally developed continents namely Europe and Northern America for the fewer status as well as much of Africa and the Middle East regions for the larger sized one (UN 2017). The average size of family members for the surveyed Gamo lowland households is higher than the national average of 4.6 members per family (CSA 2016) but lower than the survey finding of the study conducted in other 
area of Southern Ethiopia which shows the issue to be inconsistently 7.9 (Berhanu and Yoseph 2011). Besides, the generated survey data of this predictor showed that above $54 \%$ were large sized with 7-17 family members which per se has its own implication on people's vulnerability.

Education and awareness are reported as basic demographic indicators of vulnerability as less educated people are more vulnerable to hazards and their resultants with limited capability of understanding proactive and retroactive pieces of information (Adelekan 2011, Fekete et al. 2010; Prashar et al. 2012; and Zhou et al. 2014 as cited in Jeong and Yoon 2018). In the context of Southern Ethiopia, educational level of custodians in the household has implications on vulnerability of children to labor abuse i.e. among the basic social ills mainly in Gamo highlands. In this regard, Ezo (2019) concluded that the educational status of mothers and fathers has negative effect on child labor as educated fathers and mothers employ family planning (optimal fertility) with better care and support for their children that duly reduces the odds of child labor. In the study areas, $68.1 \%$ of the study households were at low educational status (illiterate, functional adult literate and grade 1-4) which is relatively consistent with the finding of Amare et al. (2020) that showed above 50\% of respondents' illiteracy and implied strong commitment of enhancing people's awareness for better coping capacity against vulnerabilities.

Farmland is also one of the basic socio-economic characteristics of the study households. Its size varied in the study areas from the lowest 0.125 hectare to the highest 19 hectares. In average, the study households possess 3.43 hectare of landholding which is much greater than the estimated national average of 0.93 hectare (CSA \& WFP 2014 as cited in Dereje 2019). The survey findings revealed that possession of farmland is not a critical problem in the study rural areas for most of the households embraced by the study. This statement is because, there was no landless respondent and even above $85 \%$ of the households owned more than 2.5 hectare to 19 hectares of farmland.

All the study sites are occupied by both early and recent relocates with differential arrival time as most of them were resettlers who came from different origins. Households with earlier arrival characteristics since 1948 have more landholding size that also was among the drivers of differential community vulnerability. That is due to the fact that population size (minimum with abundant land) at their first arrival was not like the study time with large family size i.e. around 7 in average). Hence, this condition is imperatively quoted as "First came, more served" that by itself is an implication of differential vulnerability and inequitable access to assets like landholding and the then pressure of rapid population growth. Kibrewossen et al. (2017) in their report also revealed the instance of decrement in average size of farmland in Ethiopia due to the combined effect of increasing countryside population, narrowing expansion scope of extra land and sluggish movement to be released from agriculture.

Most of land acquiring ways in Ethiopia are pursued by Gamo lowland rural people except donation and lease. The identified land accessing ways embrace official distribution, from government during resettlement scheme, taking one's own share from the family, inheritance from parents, and renting either from relatives or neighbors. The leading acquisition strategies in rank were resettlement, official distribution, and taking shares from families with $36.8 \%, 29.5 \%$, and $16.1 \%$ respectively among others. 
As part of their livelihood activities, above $90 \%$ of the sample respondents rear various domestic animals with differential ownership size. This subsector importantly helps building community resilience in the study kebeles as animals are the mainstay of people's survival. In average, the surveyed Gamo lowland rural communities owned slightly above two oxen and cows while their possession was below two for the heads of bulls, heifers, and calves as components of bovine families. Livestock farming in the study areas also embraces smaller ruminants whose value is weighed as too vital to stand against vulnerability to food and livelihood insecurity. During hard times (bad weather, crop failure, and related resultants) that enforce people to sell their animals, they most commonly give the selling priority to these animals before the big ones (cattle). Goats and sheep are dominant under such cases. The survey result indicated that from small ruminants, goats are neared by most (above 69\%) households. The targeted respondents were represented by possessive inequality of the minimum one and maximum thirty heads of goat.

\section{Community Perceptions and Understanding of Vulnerability in Gamo Lowlands}

In Africa, slum communities perceive climate change hazard in various ways of which the vast majorities understand the problem as variations in the pattern of climatic elements basically temperature and rainfall. These people also have the awareness of changing climate as it is the "act of God" and raising contamination of the atmosphere (Owusu 2016). In Ethiopia, the local people have their own perceptions or indigenous knowledge to acknowledge the happenstances of climate related natural hazards. For instance, drought recurrence and rainfall and temperature irregularities are amongst households' identified perceptions of varying climate across differential agro-ecologies (Arega 2016).

In the context of the surveyed Gamo lowlands, the local communities had their own diverse perceptions and understanding of vulnerability. Basically, the existing environmental and socio-economic conditions across the study areas boldly dictate households' vulnerability expressions. Descriptively, frequencies of responses for the provided alternatives of people's vulnerability perceptions and understanding are summarized and schematized in two perception pathways in which weight of severity for the existing conditions are strongly stressed. With varying degrees and frequencies, eleven vulnerability parameters/indicators were commonly expressed by the surveyed households. The schema in Figure 5 shows the summary of people's vulnerability perceptions and understanding with increasing and ebbing away extents of the identified predispositions. In the schema, responding to some of the basic vulnerability assessment questions as per the gaps to be filled in this study were also taken in to account. Three of these five questions were treated based on survey responses of drought vulnerable lowland rural communities.

\section{What is the extent of vulnerability?}

In literature, the first question posed in vulnerability assessment is about its extent (Hoddinott and Quisumbing 2003 as cited in Moret 2014). For this question, drought vulnerable lowland communitybased response is outlined in schematized pathway. The first pathway indicates how vulnerability is perceived in the context of drought affected lowland people. Throughout the pathway, the perceptions 
and understanding of lowland households towards vulnerability are stemmed basically from susceptibility to drought hazard and its corollaries.

Except few of the respondents, most others prioritized and iterated drought hazard along with its recurrence in their expression about perceptions and understanding of vulnerability. Besides; rainfall inconsistency, prevalence of animal diseases, insecure livelihoods, exposure to food insecurity and human disease prevalence were also among the common indicators of communities' consciousness about vulnerability. Across the pathway, the magnitude more or less becomes lessened for instance poor sociality and landlessness were not severe problems in the study areas for majority of the studied households.

Pathway two delineates the fact that from its initial areas towards its course, the extent of existing problems people perceive as vulnerability becomes worse and worse. Generally, the perception pathways imply differential extent of vulnerability perceptions based on the existing socio-economic characteristics from the lesser restraint of landholding to the severe drought exposure. This is easily understood by contouring across contradicting courses of the pathways indicated by the direction of the arrows. The color tinting of the arrows (hazardous red and warning yellow) signals the weight/ nature of happenstances that are indicative of vulnerability. Reversed mini-arrows at the progressive ends of the main arrows indicate the degree of increment or decrement of the constraints across the main arrows and what actions to prioritize in order to tackle the problems by all the concerned bodies including the victimized households

Perceiving exposure to drought hazard as rural vulnerability is identified by the vast majority of the studied households as can be seen in Figure 3. In addition to examining the perceptions and understanding of households' lowland rural vulnerability, the survey also embraced investigating what the households were vulnerable to. In the context of the study sites, 11 sorts of vulnerabilities to what households have been predisposed were provided to respond. Namely; exposure to drought, flood, landslide, human diseases, animal disease prevalence, animal death, crop failure, livelihood insecurity, food insecurity, environmental degradation and crop pest were the basic items or vulnerabilities for what the households expressed their vulnerability attitudes.

Accordingly, $96.84 \%$ of the households expressed their favorable opinions on their perceptions and understanding of rural vulnerabilities while $2.46 \%$ households did it unfavorably. The favorable and unfavorable positions of households were based on the sum of scores for the 11 items with the highest expected score of 55 as per Likert scale with five options assigning 5 for high score to represent high intensity of vulnerability perceptions and understanding. Reliability analysis was conducted to check the similarity of average scores for the items or provided eleven vulnerability perceptions and understanding questionnaire. The item statistics of the generated Cronbach Aplha showed fairly similar average scores without a lot high or low value that demanded no removal of any item. 


\section{What are the Sources of Vulnerability? "First Came, More Served" Notion}

In the context of the study areas, land is the crucial physical asset dictating households' vulnerability extent. As elaborated earlier, almost all of the study population were resettled communities with varying origins and arrival periods. During this temporal variations of their arrivals, dynamics of human population with incremental indicators at destinations was another determinant of access to landholding size. The notion "First came, more served" is fitting instance and expression of the condition in terms of land ownership. The earlier occupants who began holding in the modality of mootta (land owned/ later inherited by highland households/family members at lowlands before the current permanent settlement) for instance in Mirab Abaya district kebeles enabled the surveyed households own ample landholding size up to 19 hectares. Additionally, most earlier occupants similarly have large farmland possessions in Dugana Gamero and Tentelle rural kebeles of Boreda district. When examined watchfully, most of the factors incline to multiple classes of livelihood resources that are not equally accessed by the sampled community members. Such an unequal access to resources among societies is asserted as a factor of differential vulnerability in line with examining the impacts of changing climate (Thomas et al. 2019). In the context of Gamo lowlands, illustrated below are the identified and generalized sources of communities' socio-economic vulnerability.

Consistently, poor market and shortage of fertile land are among the concluded dynamic pressure factors that drive people's vulnerability to drought hazard in the light of recently modified PAR model (Hamis 2018). Gender, that mainly focused on female headship and age on elderly people and their especial predisposition in this study were also incorporated in the dissemination of HelpAge International (2013) among the culprits of vulnerability which agree with Gamo lowland context.

\section{Who is vulnerable?}

People resettled at the study areas originating from differential agroecology were vulnerable. This happenstance was widely observed at Dugana Gamero kebele where many highlanders from cold climatic conditions of Chencha, Kogota and Dita districts were resettled and became vulnerable to contradicting lowland climate and its resultants like malaria prevalence. Due to this trammel, many households returned back to their original abodes with in few weeks of the 2003/04 resettlement scheme not achieving the intended food security assurance (Asrat 2009).

In addition, key informants and informally contacted community members also added that especially for old aged and female headed households with no relatives and responsibly supporting bodies, vulnerability with multiple modalities is severe. In the study areas, such vulnerable sorts of people depend on supports of other community members, churches, and governmental social protection strategies like PSNP as direct beneficiaries. For these sections of the community, capacity is weak to stand against the facing challenges like food shortfalls, human and animal diseases, recurrence of drought hazard and its impacts and others. This finding coincides with what Hamis (2019) claims on the decisiveness of 
peoples' shock withstanding capacity (resilience) for economic vulnerability in Tanzania among the other things.

\section{Is Vulnerability Differential or Uniform?}

With the intention of exploring uniform or differential idiosyncrasy of vulnerability, the question; "Are all households equally vulnerable to hazards and the related adversities?" was forwarded to all survey respondents. Accordingly, the idiosyncrasy of community vulnerability in rural Gamo lowlands has two characteristics namely; differential and uniform. In the survey result, $96.5 \%$ of the respondents stated the fact that rural vulnerability is differential as all households were not equally susceptible to the existing socioeconomic irregularities. The identified causes for this status were investigated in detail and presented in consideration with the profile of drought prone lowland communities. Accordingly, the leading six factors of households' differential vulnerability were strong capacity to resist hazards (77.9\%), better/ diversified income (71.7\%), large livestock ownership (45.7\%), large landholding (35.9\%), and large family size (33.2\%).

Though with decreasing degrees, other drivers also contribute to varying vulnerability. Strong social institutions (32.2\%), low dependency ratio (28.7\%), small family size (23.9\%), male headship $(15.6 \%)$, less/ no marginalization (15.6\%), better access to water (13.8\%), and no problem of good governance $(6.2 \%)$ in this regard have their own additional weight for unequal community predisposition. Participants of key interview and FGD also strengthened this scenario as all households are not equally vulnerable being differed in their capacity or asset ownerships that help them better withstand or make easily exposed to the facing vulnerabilities. On the other side, some respondents expressed uniformity of vulnerability for households as can be observed in Figure 5. Each of the response categories and subcontents specifically account the combination of agreements expressed by the households whose sum in percent is 90,80 and $50-70$ respectively.

\section{Conclusions}

Gamo lowlands are exposed to multiple intertwined vulnerabilities for what people have varied perceptions. Communities' vulnerability perceptions and understanding widely encompass their predispositions to drought hazard, inconsistent rainfall, poor income, food shortfalls, insecure livelihoods, animal and human disease prevalence, lack of livestock, landholding and market accesses, and poor sociality. For the vast majority of the studied households (96.5\%), vulnerability is differential idiosyncratically as all households are not equally vulnerable.

Female headed, old aged, and large sized households with no supportive forces are disproportionately vulnerable to various sorts of vulnerabilities. Rural vulnerabilities in Gamo lowlands are dominantly sourced from combined effects of drought hazard, elderliness, lack of labor force, female headship, large 
dependent family members, low educational level, differential agroecology, and lack of market and information access among the others.

Eventually, for better resilience, enhancing people's perceptions and understanding of vulnerability via continuous awareness creation is imperatively recommended as the majority (68.1\%) were lowly educated. Also, access to market and water, more drought hazard coping strategies, and ways how to make large dependent family members as a remedy of vulnerability rather than becoming its cause still seek strong commitment of all the concerned stakeholders.

\section{Declarations}

Availability of data ana materials: Households' survey data entered into SPSS version 23 and used widely for used and/or analyzed during the current study are available from the corresponding author on reasonable request if it is needed in line with data and material availability. Other than these, no data were used from any dataset.

Competing interest: The authors declare that they have no conflict of interest

Funding: No funding or grant was received from any institution/ donor for this study.

Authors' Contribution: All authors contributed in the entire process of this research work responsibly. Preparing the material, data gathering and analysis as well as first draft writing were done by Thomas. Degefa and Abera reviewed and finally approved the manuscript before sending for journal publication.

Acknowledgements: The authors are thankful to Arba Minch University for sponsoring the corresponding author. Communities of the study districts, Agricultural Office Experts and Development Agents, focus group attendees, key and informal informants, and local level administrative bodies deserve respective thanks for their cooperation during field duties.

\section{Disclaimer}

The manuscript in full or partially is not previously published or not under consideration elsewhere.

\section{References}

Abera U (2013) Agricultural Modernization, Extension and People's Perception in Gamo

Highlands: Southwest Ethiopia. Open Science Repository Agriculture doi 10.7392/openacces.23050470

Akerlof L K, Delamater L P, Boules R C, Upperman R C, Mitchell S C (2015) Vulnerable Populations Perceive Their Health as at Risk from Climate Change. International Journal Environment Research Public Health 2015 (12): 15419-15433. doi:10.3390/ijerph121214994 www.mdpi.com/journal/ijerph 
Aklilu A, Alebachew A (2009) Assessment of climate change-induced hazards, impacts and responses in the southern lowlands of Ethiopia. FSS Research Report No. 4

Alemayehu A, Teshome Y, Abera U (2020) Impact of resettlement scheme on vegetation cover and its implications on conservation in Chewaka district of Ethiopia. Environmental Systems Research (2020) 9 (2): https://doi.org/10.1186/s40068-020-00164- 7

Almalki S (2016) Integrating Quantitative and Qualitative Data in Mixed Methods Research- Challenges and Benefits. Journal of Education and Learning 5 (3): 2016 ISSN 1927-5250 E-ISSN 1927-5269 Published by Canadian Center of Science and Education

Alvi H M (2016) A Manual for Selecting Sampling Techniques in Research

Amare W A, Mulusew K, Yenesew F, Hayimro E (2020) Prevalence and associated factors for rural households' food insecurity in selected districts of east Gojjam zone, northern Ethiopia: cross-sectional study. BMC Public Health (2020) 20 (202): https://doi.org/10.1186/s12889-020-8220-0

Angela C, Jeremy G C, John H, Erich R, Rainer W, Norman V (2015) Vulnerability Assessment Definitions, Indicators and Existing Assessment Methods, State of the Art Report (4) RESIN

Arega B (2016) Households' Perceptions and Adaptation Techniques to Climate Variability in DroughtProne Areas of the Amhara Region, Ethiopia Households' Perceptions and Adaptation Techniques to Climate Variability. EJSS 2 (2): 2016.

Assefa A, Berhanu A, Abebe T. (2008) Perceptions of Stakeholders on Climate Change and Adaptation Strategies in Ethiopia. Copyright @ 2008 International Food Policy Research Institute

Asrat T (2009) The Dynamics of Resettlement with reference to the Ethiopian Experience

Kimmage Development Studies Center

Balteanu D, Costache A, Sima M, Dumitrascu M, Dragota C, Grigorescu I, (2014) A participatory approach of flood vulnerability assessment in the Banat Plain, Romania. Geophysical Research Abstracts 16 EGU2014-14236, 2014

Berhanu A, Yoseph S (2011) Donkeys, Horses and Mules - their Contribution to People's Livelihoods in Ethiopia: The Brooke.

Cannon T (2008) Reducing People's Vulnerability to Natural Hazards Communities and

Resilience. Research Paper No. 2008/34, UNU-WIDER

Central Statistical Agency (CSA) \& World Bank (2013) Ethiopia Rural Socioeconomic Survey (ERSS) Survey Report May $7^{\text {th }}, 2013$. 
Central Statistical Agency (CSA) [Ethiopia] and ICF (2016) Ethiopia Demographic and Health Survey 2016. Addis Ababa, Ethiopia, and Rockville, Maryland, USA: CSA and ICF.

Chaudhury M (2017) Strategies for reducing vulnerability and building resilience to environmental and natural disasters in developing countries. World Resources Institute

Chauvet G (2015) Coupling Methods for Multistage Sampling.

Ciurean L R, Schröter D, Glade T (2013) Conceptual Frameworks of Vulnerability

Assessments for Natural Disasters Reduction. http://dx.doi.org/10.5772/55538

Coppola DP (2007) Introduction to International Disaster Management. Elsevier, Amsterdam,

The Netherlands

Creswell W J (2014) Research Design: Qualitative, Quantitative, and Mixed Methods Approaches. (4 ${ }^{\text {th }}$ Edition) SAGE Publications, Inc. ISBN 978-1-4522-2609-5 (cloth) - ISBN 978-1-4522-2610-1 (pbk.)

Dereje T (2019) Food Security and Livelihood Strategies of Rural Farm Households with Focus on Female-headed Households in Sasiga District, East Wollega Zone, Ethiopia. A Dissertation to be submitted to the Center for Rural Development in Fulfillment of the Requirements for the Degree of Doctor of Philosophy (Rural Livelihood and Development) Addis Ababa University, College of Development Studies MAY, 2019 Addis Ababa, Ethiopia

Disaster Risk Management, Environmental and Social Management Framework (2011) Disaster Risk Management and Food Security Sector: The Federal Democratic Republic of Ethiopia, Disaster Risk Management Country Plan Project, Phase I.

Ezo E (2019) Prevalence and Causes of Child Labor in Gamo Gofa Zone: The Case of Daramalo District. International Journal of African and Asian Studies www.iiste.org ISSN 2409-6938 An International Peerreviewed Journal DOI: 10.7176/JAAS 56, 2019

Fischer W, Chattre A (2016) Assets, livelihoods, and the 'profile approach' for analysis of differentiated social vulnerability in the context of climate change. Environment and Planning A 2016 48(4):789-807. DOI: 10.1177/0308518X15623278 epn.sagepub.com

Food and Agricultural Organization, FAO Ethiopia (2017) Drought Response Plan and Priorities

in 2017. Food and Agriculture Organization of the United Nations

Getachew T, Degefa T, Negussie S. (2018) Food insecurity of rural households in Boset district of Ethiopia: a suite of indicators analysis. Agriculture \& Food Security (2018) 7(65):

https://doi.org/10.1186/s40066-018-0217-x 
Habtamu T M, Tadesse T M, Amanuel Z A (2018) Farmers' perception of drought and its socioeconomic impact: the case of Tigray and Afar regions of Ethiopia. Journal of Applied Animal Research 46 (1): $1023-$ 1031, DOI: $10.1080 / 09712119.2018 .1450752$

Hamis S H (2018) Application of a PAR Model for Assessing Vulnerability to Drought Hazard in Kondoa District. Journal of Geography and Natural Disasters 8 (232): doi:10.4172/2167-0587.1000232

Hamis S H (2019) Understanding Vulnerabilities in Tanzania. Global Scientific Journals 7 (5): May 2019, Online: ISSN 2320-9186 www.globalscientificjournal.com

HelpAge International (2013) Vulnerability of Older People in Ethiopia The Case of Oromia, Amhara and SNNP Regional States. Copyright @ 2013 HelpAge International

Iloka N (2017) Perceptions of ethnicity, local knowledge and sustainable livelihoods in relation to DRR: The Case of Nsukka in South-East Nigeria. Doctoral thesis, Northumbria University International Institute of Rural Reconstruction (IIRR) (2010) Facilitating Community Managed Disaster Risk Reduction Course (CMDRR). Jamshed A, Birkmann J Feldmeyer D, Irfan Ahmad Rana A I (2020) A Conceptual Framework to Understand the Dynamics of Rural-Urban Linkages for Rural Flood Vulnerability. Sustainability 202012 (2894): doi:10.3390/su12072894 www.mdpi.com/journal/sustainability Jeong S, Yoon D (2018) Examining Vulnerability Factors to Natural Disasters with a Spatial Autoregressive Model: The Case of South Korea. Sustainability 201810 (1651): doi:10.3390/su10051651 Jha K M (Ed) (2010). Natural and Anthropogenic Disasters Vulnerability, Preparedness and Mitigation. Springer ISNB 978-90-481-2497-8 (HB)

Kibrewossen A, Hirvonen K, Minten B (2017) Farm size, food security, and welfare: Descriptive evidence from the Ethiopian highlands.

Kidane G, Debebe F, Raj A J, Gebremeskel D (2019) Studies on farmland woody species diversity and their socioeconomic importance in Northwestern Ethiopia. Tropical Plant Research 6(2): 241-249

Kinfe G., Tewodros T (2014) Risk perception and management in smallholder dairy farming in Tigray, Northern Ethiopia. Journal of Risk Research 17(3): 367-381, DOI: 10.1080/13669877.2013.815648 
Kinfe G, O’Reilly S, Lahiff E, Steiner B (2018) Cattle farmers' perceptions of risk and risk management strategies: Evidence from northern Ethiopia.

Kumar R (2011) Research Methodology a step-by-step guide for beginners. $3^{\text {rd }}$ Edition SAGE Publications Ltd

Lawson T E, Alare S R, Salifu ZR, Thompson-Hall M (2020) Dealing with climate change in semi-arid Ghana: understanding intersectional perceptions and adaptation strategies of women farmers.

GeoJournal (2020) 85: 439-452 https://doi.org/10.1007/s10708-019-09974-4

Lewis J, Kelman I (2011) Places, people and perpetuity: Community capacities in ecologies

of catastrophe.

Lomboll R, Pound B (2014) Reviewing the contribution of Send a Cow towards strengthening the resilience of farmers in the face of climate shocks and increasingly unreliable weather patterns. Send a Cow, The Old Estate Yard Newton St Loe Bath, BA2 9BR and The Natural Resources Institute, The University of Greenwich Chatham Maritime Kent, Me4 4TB

Mafi-Gholami D, Danehka,r A, Babazadeh S (2016) Analysis and selection of the best approach for vulnerability assessment in natural environments. Advances in Environmental Sciences Bioflux 8 (2):221243

Marchenzini V, Wisner B, Londe R, Saito M (2017) Reduction of vulnerability to disasters: from knowledge to action. ISBN - 978-85-7656.050.0

Martin R, Linst“adter A, Frank K, Muller B (2014) Livelihood Security in Face of

Drought Assessing: The Vulnerability of Pastoral Households. Environmental Modeling \& Software accepted October 2014

McEntire A D, Crocker G, Peters E (2010) Addressing vulnerability through an

Integrated Approach. International Journal of Disaster Resilience in the Built

Environment 1 (1): 50-64 Emerald Group Publishing Limited 1759-5908 DOI

$10.1108 / 17595901011026472$

Mekonnen HD (2018) Assessing Local Community Perceptions on Climate Change and Variability and its Effects on Crop Production in Selected Districts of Western Oromia, Ethiopia. Journal of Climatology \& Weather Forecasting 6(1): DOI: 10.4172/2332- 2594.1000216

Menberu T (2014) Population Growth and Cultivated Land in Rural Ethiopia: Land Use Dynamics, Access, Farm Size, and Fragmentation. Resources and Environment 2014 4(3): 148-161 DOI: 
10.5923/j.re.20140403.03

Ministry of Agriculture and Rural Development (MoARD) (2010) Ethiopia's agricultural sector

Policy and investment framework (PIF) 2010-2020. Retrieved from

http://gafspfund.org/sites/gafspfund.org/files/Documents/Ethiopia 5 of6CAADPPost

Compact Investment Plan (PIF) 0.pdf Poor- A Propensity Score Matching Approach

Moret W (2014) Vulnerability Assessment Methods. A Review of the Literature

Mynarska M, Riederer B, Jaschinski I, Krivanek D, Neyer G, Oláh L (2018)

Vulnerability of Families with Children: Major Risks, Future Challenges and Policy

Recommendations.

National Disaster Risk Management Commission (NDRMC) (2019) Retrieved on Wednesday, January 30, 2019

Ncube A, Tawodzera M. (2019) Communities perceptions of health hazards induced by climate change in Mount Darwin district, Zimbabwe. Jàmbá: Journal of Disaster Risk Studies 11(1): a748. https://doi.org/10.4102/jamba.v11i1.748

Nega D, Mohammed C, Bridle K, Corkrey R, McNeil D (2015) Perception of climate change and its impact by smallholders in pastoral/agropastoral systems of Borana, South Ethiopia. Springer Plus (2015) 4 (236): DOI 10.1186/s40064-015-1012-9

NURU International (2015) Quarter 4 Report.

Okaka O F, Odhiambo O, (2019) Households' perception of flood risk and health impact of exposure to flooding in flood-prone informal settlements in the coastal city of Mombasa. International Journal of Climate Change Strategies and Management 11 (4):592-606 Emerald Publishing Limited 1756-8692 DOI 10.1108/IJCCSM-03-2018-0026

Owusu M (2016) Perception and vulnerability of slum communities to climate change in Accra, Ghana. PhD Student University of Adelaide IAG Conference $29^{\text {th }}$ June, 2016

Schneiderbauer S, Ehrlich D (2004) Risk, Hazard and People's Vulnerability to Natural Hazards: A Review of Definitions, Concepts and Data, Brussels. European CommissionJoint Research Centre (EC-JRC)

Singh C, Osbahr H, Peter D (2018) The implications of rural perceptions of water scarcity 
on differential adaptation behavior in Rajasthan, India. Regional Environmental Change

(2018) 18: 2417-2432 https://doi.org/10.1007/s10113-018-1358-y

Singh R S, Eghdami R M, Singh S (2014) The Concept of Social Vulnerability: A Review from Disasters Perspectives. International Journal of Interdisciplinary and Multidisciplinary Studies (IJIMS) 1 (6): 71-82. Available online at http://www.ijims.com ISSN: $2348-0343$

Slater W F (2018) Vulnerability Management: A Practitioner's Perspective Evolve Security

Academy.

Thabane K (2015) Determinants of Vulnerability to Livelihood Insecurity at Household

Level: Evidence from Maphutseng, Lesotho. Journal of Agricultural Extension 19 (2):

Thomas K, Hardy R D, Lazrus H, Mendez M, Orlaves B, Rivera-Collazo I, Roberts T, Rockman M, Warner B, Winthrop R (2019) Explaining differential vulnerability to climate change: A social science review. WIREs Climate Change 10: e565. https://doi.org/10.1002/wcc.565 United Nations

United Nations, Department of Economic and Social Affairs, Population Division (2017) Household Size and Composition Around the World 2017. Data Booklet (ST/ESA/ SER.A/405).

Yoseph M, Habtemariam K, Mengistu K, Degnet A, Ute S (2015) The effect of drought risk perception on local people coping decisions in the Central Rift Valley of Ethiopia. Journal of Development and Agricultural Economics 7(9): 292-302, September, 2015 DOI: 10.5897/JDAE2015.0674

Wisner B, Blaikie P, Cannon T, Davis I (2004) At Risk: Natural Hazards, People's

Vulnerability and Disasters. (Second Edition), Routledge, London and New York

Wisner B (2016) Vulnerability as Concept, Model, Metric, and Tool. Oxford Research

Encyclopedia of Natural Hazard Science DOI: 10.1093/acrefore/9780199389407.013.25

World Meteorological Organization (2012) Standardized Precipitation Index User Guide (M. Svoboda, M. Hayes and D. Wood). (WMO-No. 1090), Geneva.

\section{Tables}

Table 1 Population Identification and Proportional Allocation 


\begin{tabular}{|c|c|c|c|c|c|c|c|c|c|c|c|}
\hline \multirow[t]{2}{*}{ Woreda } & \multirow[t]{2}{*}{ Kebele } & \multicolumn{3}{|c|}{ Total Population } & \multicolumn{3}{|c|}{$\begin{array}{l}\text { Household } \\
\text { Population }\end{array}$} & \multirow[t]{2}{*}{$\begin{array}{l}\text { Allocation } \\
\qquad \%\end{array}$} & \multicolumn{3}{|c|}{$\begin{array}{l}\text { Selected Sample } \\
\text { /Respondents/ }\end{array}$} \\
\hline & & $M$ & $\mathrm{~F}$ & $\mathrm{~T}$ & M & $\mathrm{F}$ & $\mathrm{T}$ & & $\mathrm{M}$ & $\mathrm{F}$ & $\mathrm{T}$ \\
\hline \multirow[t]{2}{*}{$\begin{array}{l}\text { Mirab } \\
\text { Abaya }\end{array}$} & $\begin{array}{l}\text { Fetele } \\
\text { Doronje }\end{array}$ & 561 & 563 & 1124 & 138 & 20 & 158 & \multirow{4}{*}{28.81} & 39 & 6 & 45 \\
\hline & Doshe & 809 & 779 & 1588 & 201 & 36 & 237 & & 58 & 10 & 68 \\
\hline \multirow[t]{2}{*}{ Boreda } & Tentelle & 500 & 601 & 1101 & 102 & 11 & 113 & & 30 & 3 & 33 \\
\hline & $\begin{array}{l}\text { Dugana } \\
\text { Gamero }\end{array}$ & 1423 & 1482 & 2905 & 454 & 27 & 481 & & 131 & 8 & 139 \\
\hline Total & & 3293 & 3425 & 6718 & 895 & 94 & 989 & & 258 & 27 & 285 \\
\hline
\end{tabular}

Source: Tabulated by the Authors (2020)

Table 2 Categorized Causes of Uniform Vulnerability in Gamo Lowlands

\begin{tabular}{|lll|}
\hline Response Categories & & \\
\hline Category 1 (90\%) & Category $2(80 \%)$ & Category $3(50 \%-70 \%)$ \\
\hline Low living standard & Low educational status & Oldness \\
\hline High dependency ratio & Lack of livestock & Female headship \\
\hline Lack of good governance & Lack of water or drought & Backward cultivation method \\
\hline Environmental hospitability & Capacity difference & Lack of market \\
& & Large family size \\
\hline
\end{tabular}

Source: Survey Finding (2020)

\section{Figures}




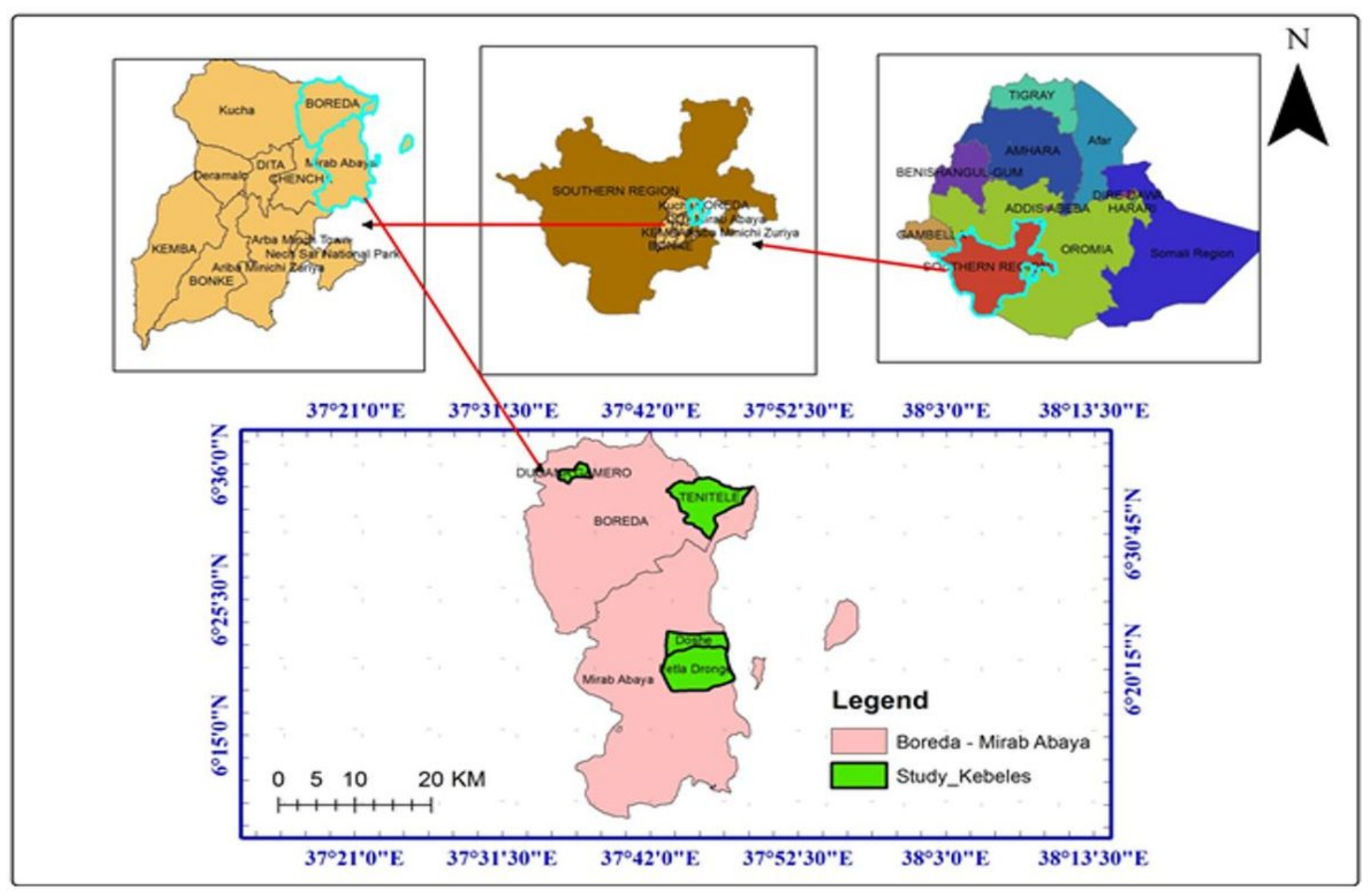

\section{Figure 1}

Location Map of Study Areas. Note: The designations employed and the presentation of the material on this map do not imply the expression of any opinion whatsoever on the part of Research Square concerning the legal status of any country, territory, city or area or of its authorities, or concerning the delimitation of its frontiers or boundaries. This map has been provided by the authors.
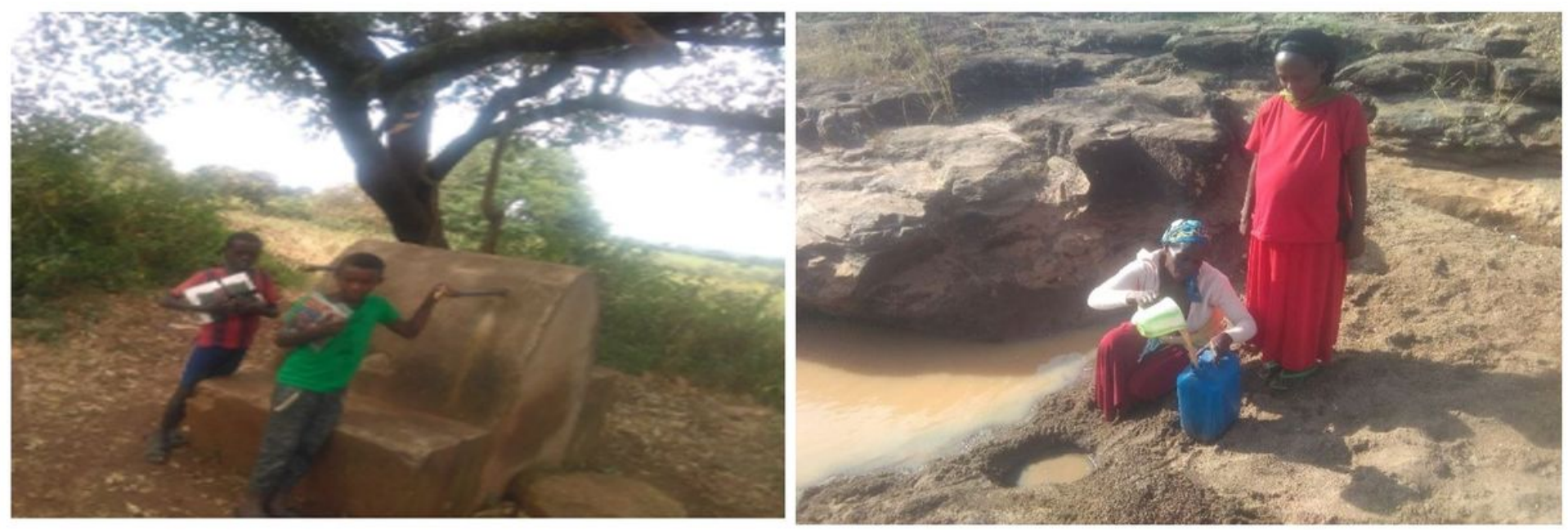

Figure 2 
Some Observations on Water Tragedy in Tentelle Kebele Source: Field Photo (2020)

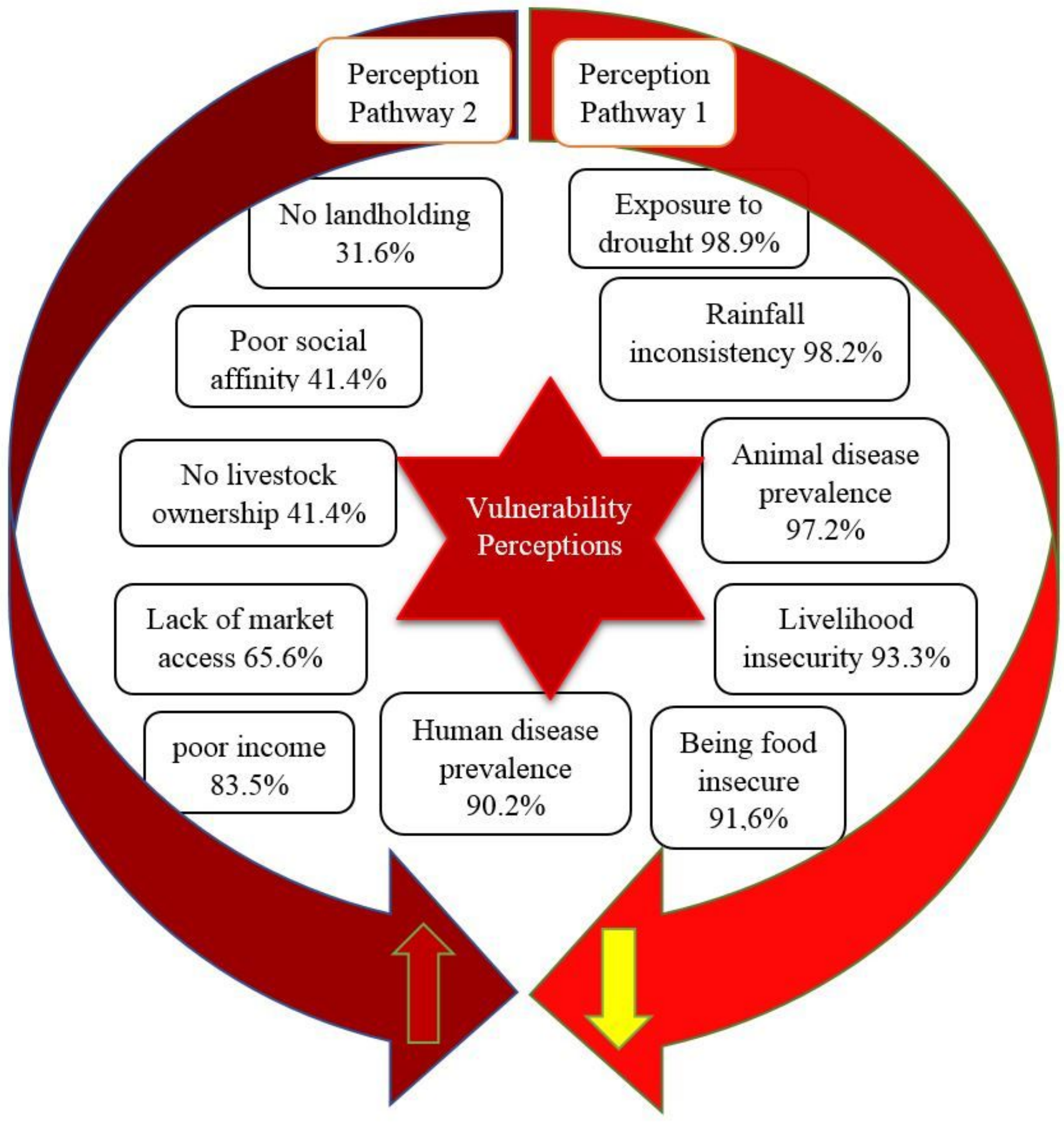

Figure 3

Schematic Pathways of Vulnerability Perceptions and Understanding Source: Survey Output Own Formulation (2020) 


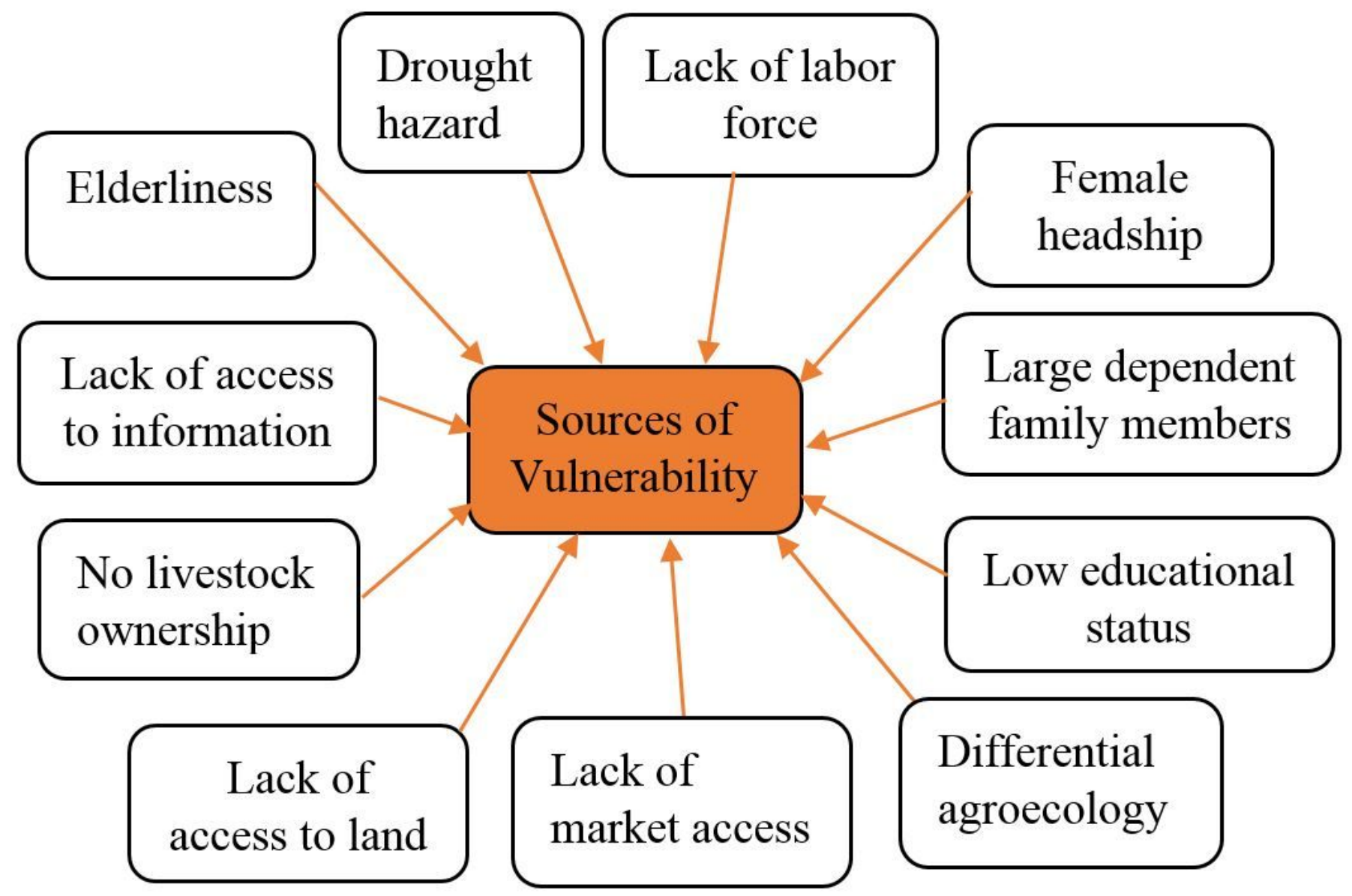

Figure 4

Identified Sources of Community Vulnerability in Gamo Lowlands Source: Survey Result (2020) 